\title{
Large Eddy Simulation of Plume Dispersion behind an Aircraft in the Take-off Phase
}

\author{
S. S. Aloysius and L. C. Wrobel \\ School of Engineering and Design, Brunel University, Uxbridge UB8 3PH, UK
}

\begin{abstract}
The aim of this paper is to provide an investigation, using large eddy simulation, into plume dispersion behind an aircraft in co-flowing take-off conditions. Validation studies of the computational model were presented by Aloysius and Wrobel (2009) and a study of the flow and dispersion properties of a double-engine aircraft jet was presented by Aloysius et al. (2007), in which only the engine was modelled. In this paper, the complete geometry of a Boeing 737 is modelled and investigated.

The current work represents a contribution towards a better understanding of the source dynamics behind an airplane jet engine during the take-off and landing phases. The information provided from these simulations will be useful for future improvements of existing dispersion models.
\end{abstract}

\section{Introduction}

There is a growing interest on airport local air quality issues as more and more passengers use this method of transportation. According to Schäfer et al. (2003), 15,000 aircraft are already populating the sky and an estimated 2,200 billion of passenger kilometres are flown each year. It is forecasted by Graham and Raper (2003) that future air traffic movements will increase at a mean annual rate of 5 to $7 \%$.

Even though most engines have become more fuel efficient and less pollutant, the expansion of air traffic more than compensates for this reduction, maintaining the high levels of emissions locally and globally. Local problems created by high levels of emission are poor air quality and environmental phenomena like smog (Rogers et al., 2002). Local pollution contributes to global problems in the form of depletion of the ozone layer and global warming. Around 3.5\% of the global warming from human activity comes from air transportation, and it is predicted that this figure will rise up to $15 \%$ by 2050 if no measures are taken to control air traffic, according to the intergovernmental panel on climate change (Penner et al., 1999).

Using the ALAQS-AV inventory tool, Celikel et al. (2004) found that approximately $80.7 \%$ of the total emissions of $\mathrm{NO}_{\mathrm{x}}$ around Zurich airport in the year 2003 come from aircraft sources. Because of the spatial and temporal resolutions needed for a complete airfield simulation, the emissions from moving sources are not properly accounted for in most commonly used dispersion modelling software. An increased knowledge into the local source dynamics is needed so that this information can be properly included into these models.

Recent studies have seen the introduction of an advanced CFD technique based on Large Eddy Simulation (LES) for studying local emission dispersion at an airport (Aloysius et al., 2006). It was found that this model can provide a better insight on the fluid mechanics and valuable source dynamics information for more popular Gaussian and Lagrangian models. 
In order to provide better understanding and knowledge of the flow physics associated with an aircraft in the take-off phase, a staged approach was used. Aloysius and Wrobel (2009) presented numerical simulations of the dispersion of buoyant free and wall jets in a co-flowing take-off condition. This first step allowed the validation of the CFD codes and a proper assessment of the impact of a solid boundary on the fluid properties. Aloysius et al. (2007) included the engine geometry in the model for the case of a double-engine aircraft, and studied the effect of the geometry on the fluid flow and plume dispersion when the aircraft is subjected to different wind conditions. The current paper represents a further step that aims at a better understanding of the plume dispersion process when the complete aircraft is modelled, and at providing some knowledge on the influence of different aircraft devices such as the wings and the stabilizers in the dispersion process. Previous research in this field was conducted by Koutsourakis et al. (2006) for the purpose of determining the best positioning for LIDAR equipment to measure pollutant concentrations. However, this study modelled the jet engine as point sources emitting from the ground and did not include any part of the aircraft geometry.

The results obtained in the current study are compared with the two-point source simulation of Koutsourakis et al. (2006), with the double-engine simulation of Aloysius et al. (2007), and also with some available LIDAR measurements taken at Manchester airport by the Manchester Metropolitan University (MMU) team.

\section{Numerical methods}

The simulation of the complete aircraft geometry employs the commercial CFD solver FLUENT 6.3, which has the capability to complete high accuracy simulations using LES turbulence models. The details of the numerical solver are explained in previous papers (Aloysius and Wrobel, 2009; Aloysius et al., 2007). Validation tests were also presented for the case of free and wall jets (Aloysius and Wrobel, 2009), and will not be repeated here.

\subsection{Geometry and boundary conditions setup}

The computational domain includes the runway length $(1,600 \mathrm{~m}$ taken from the B737 handbook chart for a standard day at Zurich airport elevation of 1,416 feet and a maximum take-off weight of 63,000kg), a complete Boeing 737-300 aircraft geometry with its most commonly used engine (CFM56-3C-1), and a downwind area for dispersion purposes. The total control volume dimensions are $2,100 \mathrm{~m}$ in the horizontal direction and $90 \mathrm{~m}$ in both vertical and lateral directions. The airplane is clean, with no winglets or high-lifting devices such as flaps or slats attached to it. The undercarriage was omitted to simplify the CFD model. Similarly to the presence of the fuselage, the undercarriage will slow down the plume penetration downwind even further and allow the plume breakup process to start earlier. The headwind condition allows the use of symmetry, so that only half of the aircraft needs to be represented.

The LES model adopted is the Dynamic Smagorinsky model described in detail in Aloysius and Wrobel (2009). Validation was carried out through a staged approach starting from a single engine free in the atmosphere and increasing the complexity step-by-step towards a complete representation of an aircraft on the runway.

The take-off procedure, according to the ICAO time-in-mode, lasts for 42 seconds for all types of aircraft; it is assumed here that during this period the aircraft will travel parallel to the runway and no rotation will take place. 
Previous studies by Aloysius (2008) and Aloysius et al. (2007) led to efficient mesh distributions and helped reducing the mesh density where it is not needed, hence reducing computational time. The work on the double-engine jet presented by Aloysius et al. (2007) showed that the first $800 \mathrm{~m}$ are governed by the jet regime and the rest of the control volume will be completely filled gradually by the dispersing plume.

In the first $800 \mathrm{~m}$, a very fine mesh is assigned close to the aircraft to capture some of the flow physics associated with its geometrical features, such as wake vortices. After that distance, a ratio is assigned allowing a gradual expansion of the mesh density in order to capture the dispersion length and height downwind with acceptable results. The whole domain is split into three major volumes of different sizes:

- The airplane volume: This volume contains nine sub-volumes with four unstructured and five structured meshes. The airplane is at break release point, and the volume is meshed with a completely unstructured mesh. The mesh setting for the airplane geometry employs a size function on the wing, the horizontal and vertical stabilizers and the engine inlet and outlet, as shown in Fig. 1. The size function gradually decreases the mesh density away from these elements, taking particular attention to those geometric effects. The half aircraft volume alone constitutes a mesh of 354,034 cells, which is almost half of the total density (750,677 cells) for this particular major volume.

- The intermediate downwind volume: This second main volume is also divided into nine sub-volumes of different mesh densities but containing only structured meshes. The length goes from the tail of the airplane to a distance of about 27 wingspans behind it. From the studies of Aloysius et al. (2007), it was found that only the three volumes surrounding the airplane geometry have major influence on the solution accuracy. For this purpose, these are finer than the other six volumes in terms of mesh density $(1,192,800$ out of the total $1,715,800$ cells for this particular major volume).

- The final downwind volume: The same configuration as the intermediate downwind volume was set up but here from 27 to 70 wingspans. Aloysius et al. (2007) found that the plume will nearly reach out the whole control volume. For this reason, the mesh density is homogeneous and accounts for $1,286,800$ cells in this final downwind volume.

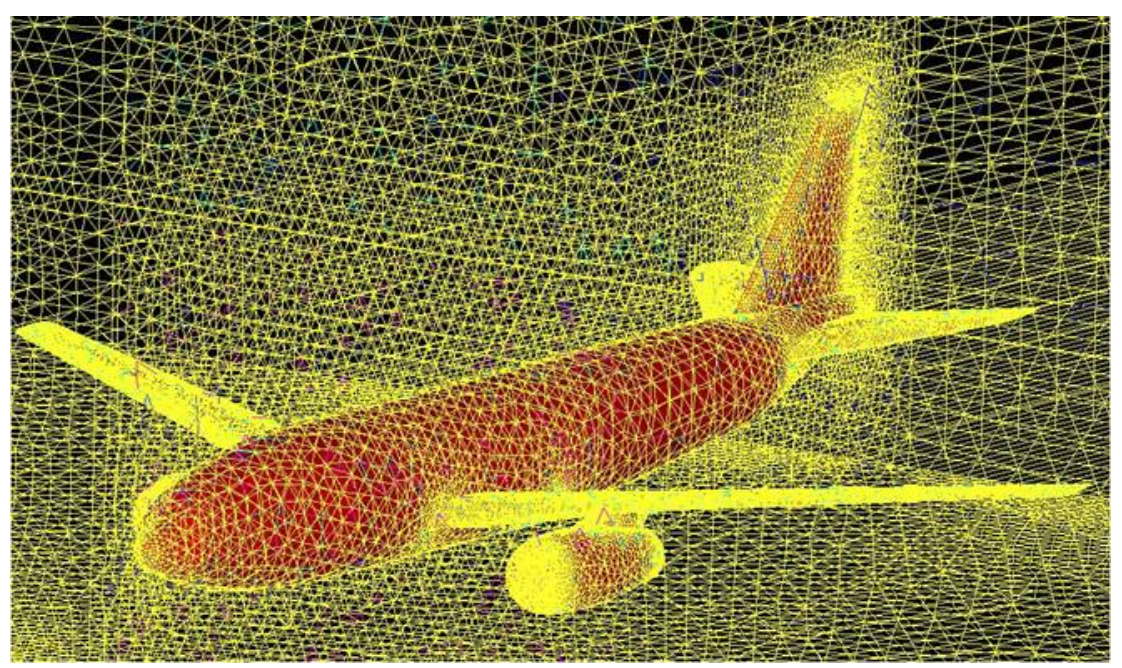

Fig. 1 - Complete Boeing 737-300 aircraft geometry 
Similarly to the work presented by Aloysius et al. (2007), the complete geometry of the airplane is kept stationary and the replication of its acceleration is done by modifying the inlet velocity via a user-defined function in FLUENT. The acceleration value used is similar to that of Koutsourakis et al. (2006)

The boundary condition assigned to the engine exhaust is the mass flow inlet with the parameters found in Archer and Saarlas (1996) and Jenkinson et al. (1999). The diameter of the engine is $0.93 \mathrm{~m}$ and is flow is fully turbulent at its source. The mass flow rate of the CFM56-3C-1 engine is $322 \mathrm{~kg} / \mathrm{s}$ and the exhaust temperature is $690 \mathrm{~K} . \mathrm{NO}_{\mathrm{x}}$ is the considered species for the current simulation and the mass fraction of the concentration is $0.74 \times 10^{-4}$. The simulation was run using the International Civil Aviation Organisation (ICAO) standard for take-off of 42 seconds at $100 \%$ thrust setting. Only a headwind with velocity of $2.5 \mathrm{~m} / \mathrm{s}$ was investigated so that results can be compared with the work from Koutsourakis et al. (2006) using a two-point source, and with those of Aloysius et al. (2007) who modelled a double-engine aircraft jet.

\section{Results and discussions}

\subsection{Analysis of plume dispersion after 10 seconds}

\subsection{1. $\mathrm{NO}_{\mathrm{x}}$ concentration study}

Spanwise direction:

Fig. 2 represents contour plots of $\mathrm{NO}_{\mathrm{x}}$ concentration for the double-engine and the complete aircraft geometry simulations after $10 \mathrm{~s}$, for a spanwise plane cutting through the centre of the jet exhaust $(1.37 \mathrm{~m}$ above the ground). For better clarity, only half of the simulation was plotted and analysed.

It can be noticed that the dispersion patterns are very different; the doubleengine simulation produces a smooth and longer dispersion plume of about 365 diameters whereas the complete geometry of the airplane creates some instabilities causing a shorter penetration downwind of about 20 diameters less than the doubleengine simulation.

The spanwise spread of the complete aircraft simulation starts a bit lower than its double-engine counterpart, but there is an enhancement of spanwise spreading for the complete aircraft simulation at about 65 diameters. 


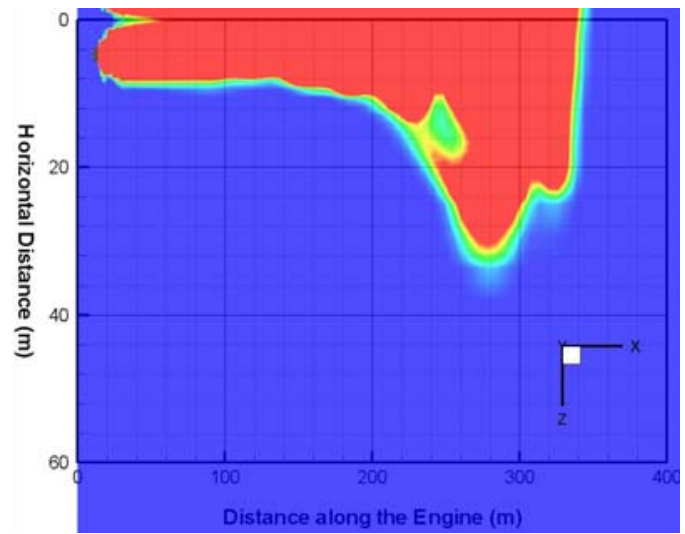

Double-engine simulation

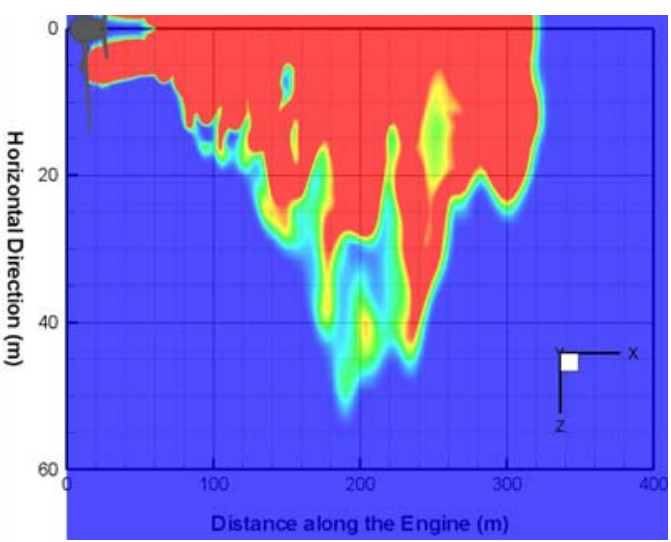

Complete aircraft simulation

Fig. 2 - Horizontal dispersion comparison between the double-engine and the complete aircraft geometry simulations after 10s

\section{Vertical direction:}

A comparison of the vertical dispersion presented in Fig. 3 illustrates several differences. There is a much deeper penetration through the control volume for the double-engine simulation but, on the other hand, the complete aircraft simulation exhibits higher dispersion in the vertical direction.

PPM of NOx: $0.010101 \quad 0.212121 \quad 0.414141 \quad 0.616162 \quad 0.818182$

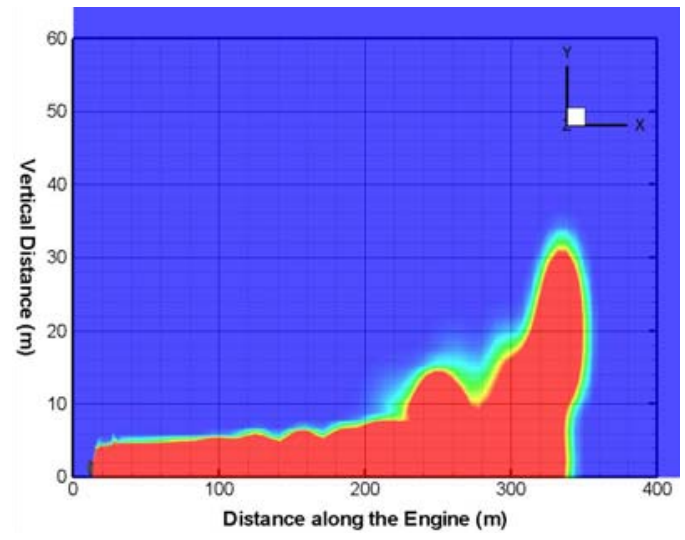

Double-engine simulation

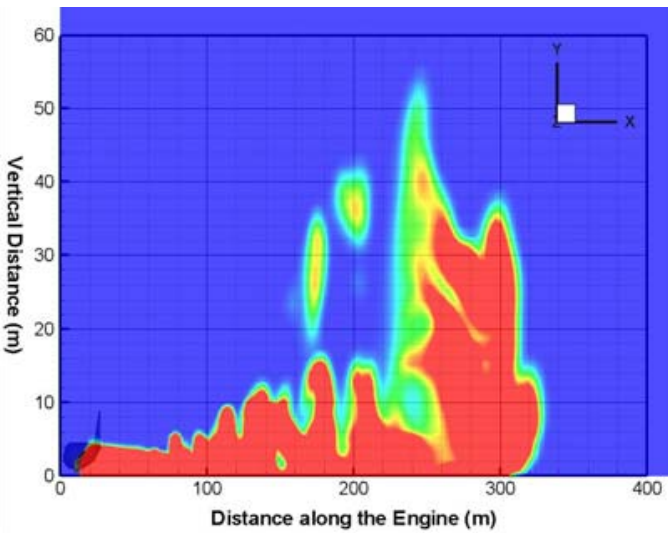

Complete aircraft simulation

Fig. 3 - Vertical dispersion comparison between the double-engine and the complete aircraft simulations after 10s

The initial spreading is lower for the complete aircraft simulation until about 75 diameters from the engine, where the growth is sharply higher than the doubleengine simulation. To understand such process, it is important to study the vortical structures formed by the dispersion process. 


\subsubsection{Vortical structure study}

Interesting characteristics can be observed as the plume evolves through time. Fig. 4 represents the spanwise vorticity profile behind the complete aircraft after 10s; the results can be compared with those of Aloysius and Wrobel (2009). The situation is similar to a jet above the ground in a co-flowing wind condition. Several features presented in that paper can be recalled, especially the role of the spanwise vortices on the flow behaviour. It can be clearly seen from Fig. 4 that the flow undergoes a clinging length before the plume lifts from the ground. The positive spanwise vortices are governed by the buoyancy effect which lifts the plume at higher distances above the ground.

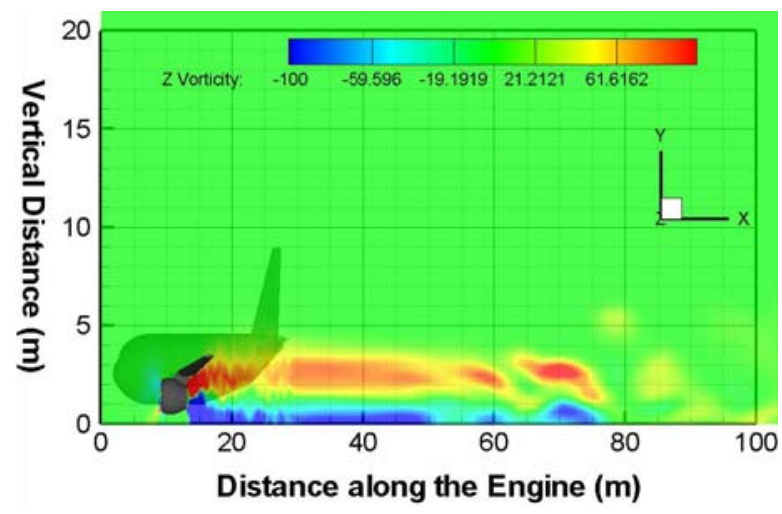

Fig. 4 - Spanwise vorticity profile behind the complete aircraft simulation after 10s

At very small distances behind the jet nozzle, the effects of the fuselage and wing geometry reduce the initial rate of spread in the horizontal and vertical directions, as shown in Fig. 2 and Fig. 3. From the engine exhaust to a distance of $120 \mathrm{~m}$ behind it, the rate of spread both in the vertical and horizontal directions seems to be lower than for the double-engine simulation; it is believed that this is due to the geometry of the aircraft fuselage in the horizontal direction and to the geometry of the wing in the vertical direction. The aircraft body acts as a wall for a short distance and, similarly to the ground effect, restricts the flow from spreading wider. The geometry of the wing is the only obstructing component in the vertical direction and can only be the influence that governs the vertical spread of the plume. These combined perturbations are also the cause of a slower penetration of the plume and a faster buoyancy triggering effect.

Fig. 5 represents an iso-surface of $12 \mathrm{ppm}$ of $\mathrm{NO}_{\mathrm{x}}$ plotted with streamwise vorticity. Comparing Fig. 5 with an equivalent figure from Aloysius et al. (2007) for the double-engine simulation shows that the plume penetration length is deeper in the current case, as discussed previously. Counter-rotating streamwise vortices wrapping around the plume and creating sinusoidal instabilities lead to a break-up, as observed in Fig. 5. The detached high level of concentration is a product of this break-up process. The transport mechanism associated with it can also be recalled from Aloysius et al. (2007), who stated that the streamwise vortices after breaking the plume concentration are the ones transporting the plume in the horizontal direction whereas a combination of all vortices affects the vertical direction, enhancing the growth rate. 

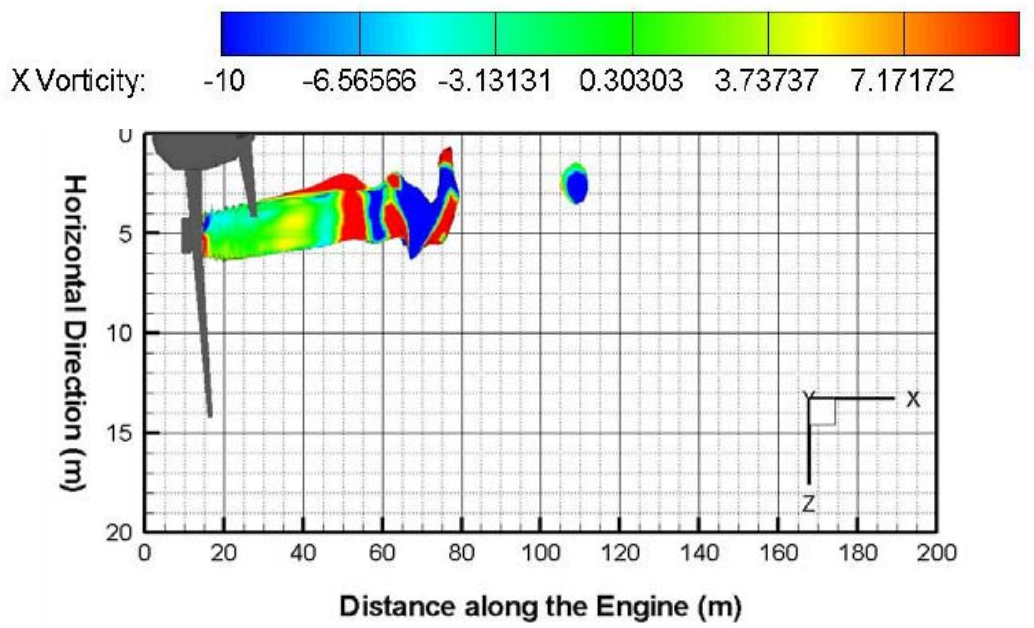

Fig. 5 - Iso-surface of 12ppm of $\mathrm{NO}_{\mathrm{x}}$ plotted with $\mathrm{X}$-vorticity for the complete aircraft simulation after 10s

To illustrate this, graphs were taken at 219.4 diameters behind the engine for the horizontal direction, which corresponds to a localised high concentration at about 40m, Fig. 6(a), and at 217.2 diameters behind the engine in the vertical direction, which corresponds to a localised high concentration at about 36 m, Fig. 6(b). In the horizontal direction, at the locations of the localised concentrations (at about $40 \mathrm{~m}$ ), the streamwise vortices (X-Vorticity) are the most dominant. In the vertical direction, on the other hand, it is a combination of all vortices (X-Vorticity, Y-Vorticity and ZVorticity) that plays a role in the transport, also enhancing the buoyancy effect at the same time. The peak of the X-Vorticity at about $10 \mathrm{~m}$ above the ground is believed to be due to a combination of the breakup process and the impact of the ground effect on the flow (Aloysius et al., 2007). When studying a jet with and without a solid boundary, Aloysius (2008) reported that one of the main differences concerned the spreading in the spanwise direction caused by streamwise vortices. This was argued to be the consequence of a thin layer just above the ground that creates counter-rotating streamwise vortices on either side of the jet, which pump and entrain the surrounding fluid at rest.

The streamwise vortices result solely from the "self-induced" jet rotation due to counter-rotating vortices wrapping around the plume as in the case of a doubleengine (Aloysius et al., 2007). One can argue that these can also come from either the wing's or the horizontal stabilizer's tip, as both generate streamwise vortices. This is true later in the simulation, but at this point the magnitude of streamwise vortices generated by these geometrical features is not strong enough to alter the flow behaviour. 


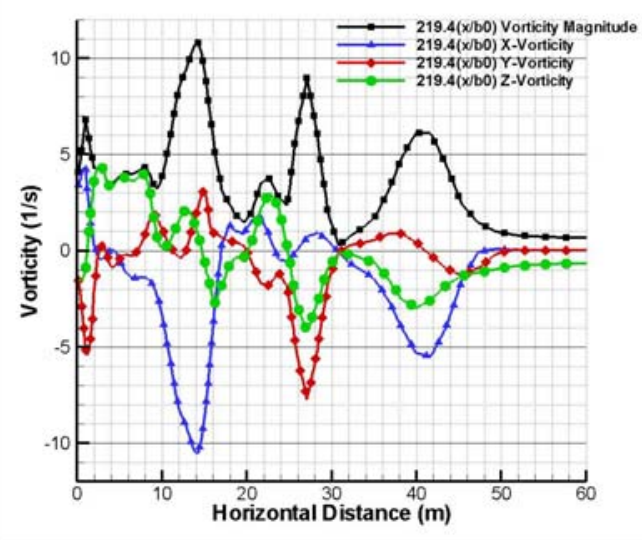

(a)

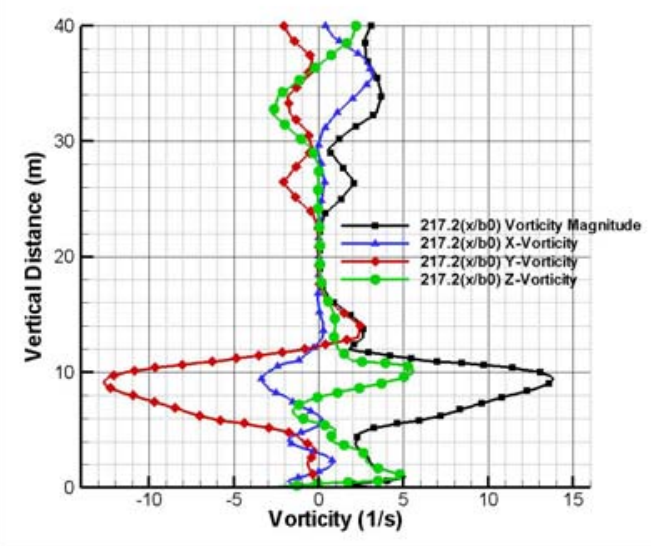

(b)

Fig. 6 - Horizontal and vertical vorticity distributions at different distances behind the complete aircraft engines, with $b 0$ the engine diameter

\subsection{Analysis of the plume dispersion after 42 seconds}

3.2.1. $\mathrm{NO}_{\mathrm{x}}$ concentration study

A concentration iso-surface was plotted and analysed for the double-engine and complete aircraft simulations because of the difficulty of plotting the different figures without distorting considerably the scale, and also to demonstrate a complete picture of the dispersion pattern at different heights above the ground.

Fig. 7 shows iso-surfaces of $\mathrm{NO}_{\mathrm{x}}$ concentration for the double-engine and the complete aircraft simulations. Several differences can be observed from this figure. Firstly, the sinusoidal instabilities created by the plume lead to a breakdown of its core and the transport by vortices in each direction. As discussed in Aloysius et al. (2007), there are also mutual interactions created by the presence of the two jet plumes, all of which lead to a break in symmetry. Secondly, the plume penetration length for the complete aircraft simulation is about 1,860m (2,000 engine diameters) behind the exhaust, whereas for the double-engine simulation it is extended by a further 40m (43 diameters). Without any geometrical disturbances, the flow was allowed to travel deeper. Horizontally and vertically, the inverse is produced. There is much wider and higher plume dispersion for the complete aircraft simulation as compared with the double-engine simulation. In numbers, the plume for the complete aircraft simulation spreads up to 50m (54 diameters) horizontally and $80 \mathrm{~m}$ (86 diameters) vertically, while the double-engine plume extends to about $46.5 \mathrm{~m}$ (50 diameters) horizontally and 50m (54 diameters) vertically. This enhancement of dispersion in the horizontal and vertical directions is due to streamwise vortices, as will be shown later.

Another point to be noticed is that the double-engine plume actually rises above the ground at about 338m (363 diameters) behind the engine exhaust. This characteristic was not observed for the complete aircraft simulation as several disturbances were created to disable this phenomenon. This point will be discussed in greater detail in the next section. 

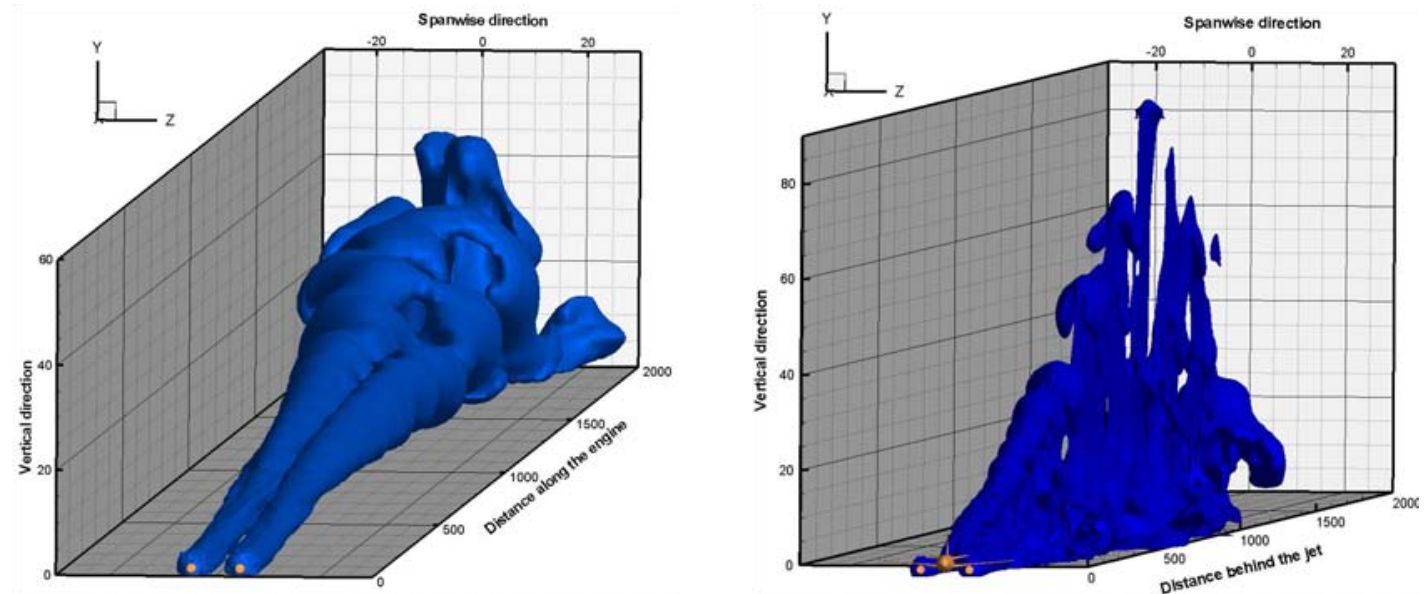

Fig. 7 - Iso-surface of 1ppm comparison between double-engine and complete aircraft simulations after $42 \mathrm{~s}$

\subsubsection{Vortical structure study}

Similarly to the previous time level and recalling some of the discussions presented by Aloysius and Wrobel (2009) and Aloysius et al. (2007), it was found that the near field is very much influenced by the spanwise direction vortices and these were found to be the ones that act as conveyors to disperse the plume downwind. As these vortices start to decrease in magnitude, a transition was observed. Due to the "self-induced" rotation as the plume weakens, as shown in Fig. 8, streamwise vortices take over and transport the plume horizontally, whereas a combination of all vortices disperses the plume vertically. The scale was changed in Fig. 8 to fit the complete figure.

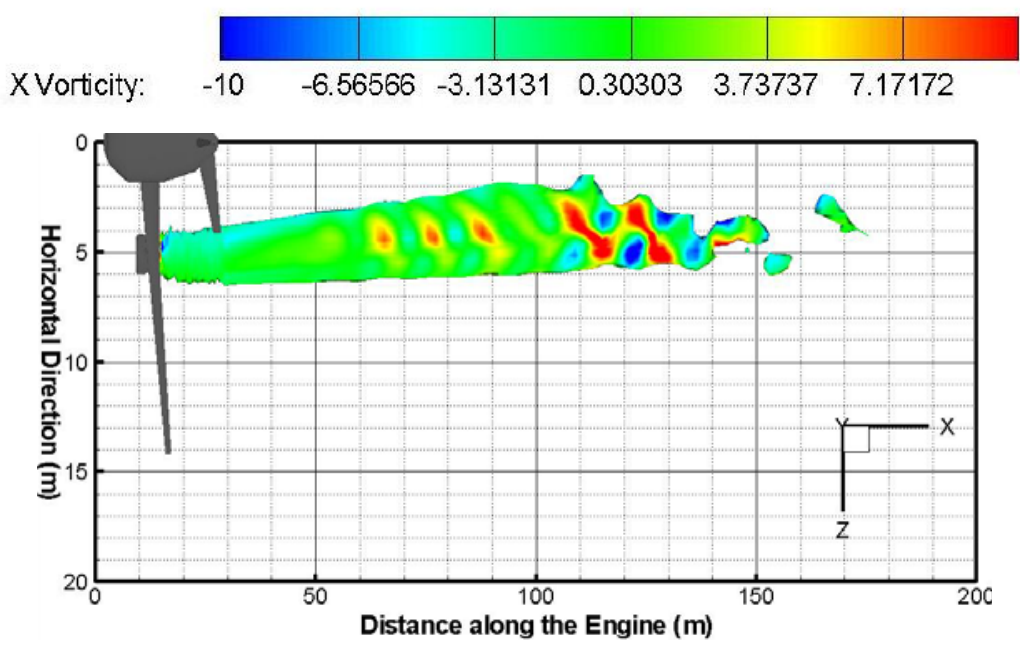

Fig. 8 - Iso-surface of 12ppm of $\mathrm{NO}_{\mathrm{x}}$ plotted with X-Vorticity for the complete aircraft simulation after $42 \mathrm{~s}$

In addition to the above dynamics, it was found that the enhancement of the streamwise vortices leads to greater plume dispersion both in the horizontal and vertical directions. These were due to some geometrical disturbances of the vortices created by the wing and the horizontal stabilizer. Fig. 9 shows a comparison of their tip vortices a few jet diameters behind these devices; the arrows represent the flow pattern in the Y-Z plane and the magnitude of the vortices is shown by the scaled contour plot. The differences between them are related to the flow rotation; the flow over the wing creates a negative rotation around the streamwise direction at the tip, 
whereas the horizontal stabilizer has positive rotation at its tip. It should be noted that the horizontal stabilizer has no settings such as a trim. This is expected as the horizontal stabilizer is in fact an inverted wing, but what is not expected is the impact it has on the dispersion pattern.

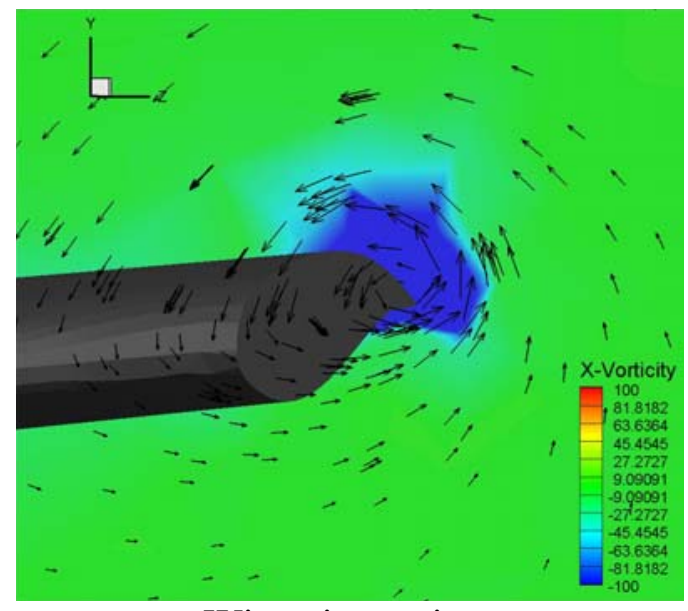

Wing-tip vortices

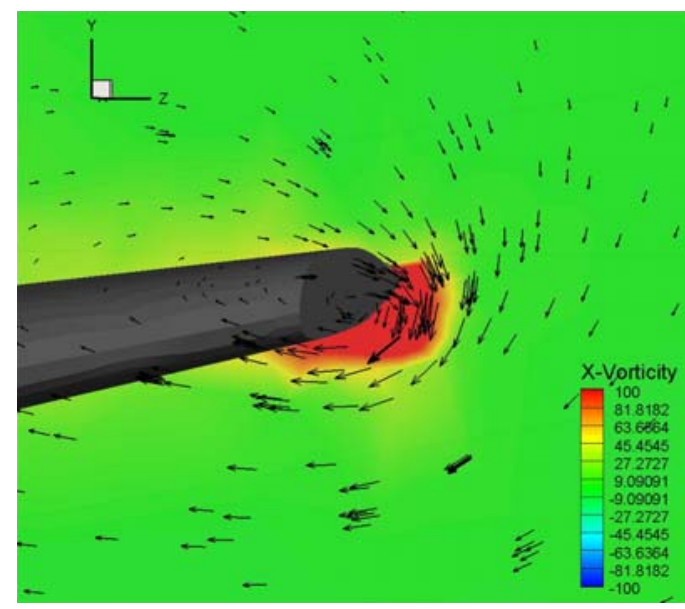

Horizontal stabilizer tip vortices

Fig. 9 - Wing and horizontal stabilizer tip vortices

Because the horizontal stabilizer is located just after the jet exhaust at about 0.96 engine diameters and in the way of the plume as it starts to spread, it will be the first to affect the flow. Its disturbance is characterised by an enhancement of the vertical dispersion as can be seen in Fig. 10. Part of the engine's exhaust is attracted by the rotation of the fluid created by the horizontal stabilizer's tip and spreads upward.

The influence of the wing tip can only be observed further away from the engine exhausts, when the jet plume has spread sufficiently laterally to meet the wingtip vortices core. The distance from the wing tip to the centre of the engine is about $9.2 \mathrm{~m}$ (9.9 diameters). Its disturbance of the flow pattern is characterised by an enhancement of the lateral dispersion. Fig. 10 clearly shows this; the $\mathrm{NO}_{\mathrm{x}}$ plume rolls around the negative $\mathrm{X}$-vortices core and is spread laterally, at low distances from the ground.

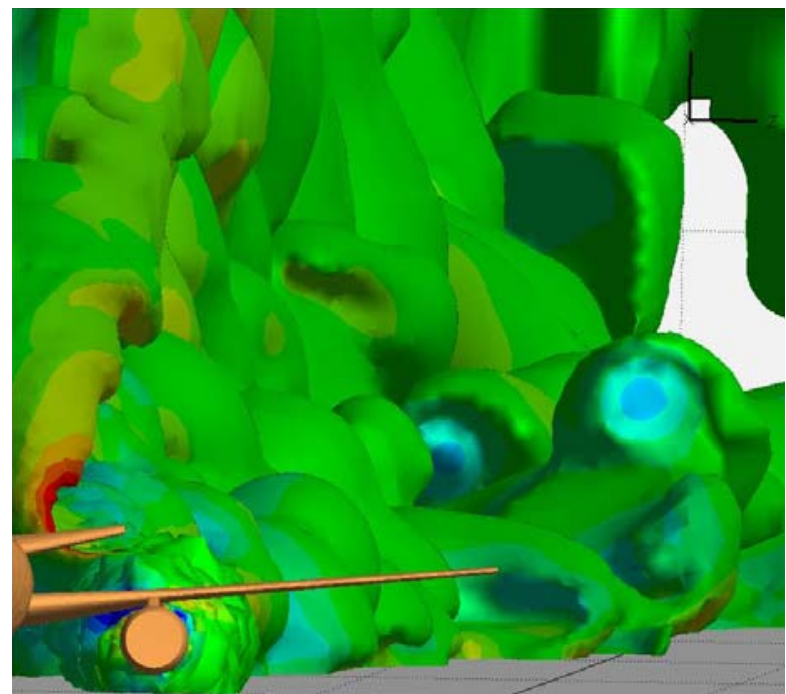

Fig. 10 - Iso-surface of $1 \mathrm{ppm}$ of $\mathrm{NO}_{\mathrm{x}}$ plotted with $\mathrm{X}$-vorticity 
The knowledge of these streamwise vortices, especially around the wing tip, is of extreme relevance in air traffic management as they can help understand and quantify better time delay separations between aircraft in different phases of flight. As well as reducing delays in air traffic and increasing airport capacity, there are also gains in fuel saving which results in emission reduction (Gerz et al., 2002). Streamwise vorticity contour plots along the chord of a NACA 2415 airfoil have been produced by Ghias et al. (2005). At the trailing edge of the wing, the vorticity contour resembles the one presented in Fig. 9 and has about the same magnitude. Both simulations are for a static wing and do not take into account the rotation exerted by the aircraft. The effect of this rotation would mean an increase in the wing-tip vortices and a slight reduction in the horizontal stabilizer tip vortices.

\subsection{Comparison with other studies}

Koutsourakis et al. (2006) simulated a Boeing 737 aircraft take-off with a RANS turbulence model and with jets emitted as point sources. The results are in good correlation with the current simulations, as the dispersion length for 1ppm in Koutsourakis et al. (2006) is approximately 2,050 engine diameters behind the jet nozzle after 40s. While the double-engine jet simulation of Aloysius et al. (2007) predicted a plume penetration length of about 2,043 diameters at 42s, the complete aircraft simulation plume penetration at 42s is even shorter at about 2,000 diameters behind the jet nozzle. A similar comparison is obtained after 10s, when the complete aircraft simulation plume penetration was about 333 diameters, the double-engine simulation was about 353 diameters and the two-point source simulation was approximately 430 diameters. This reinforces the fact that the complete geometry of the aircraft restricts the flow penetration downwind as previously discussed.

The results of Koutsourakis et al. (2006) also show that the lateral extent of the plume penetration for $1 \mathrm{ppm}$ is about 36 diameters at 40s. The complete aircraft simulation produces a lateral spread of 54 diameters, which is larger than both the double-engine (50 diameters) and the two-point source simulations. The situation is now reversed, supporting the argument that the wing-tip vortices enhance the lateral dispersion. A similar comparison at 10s also reveals the same behaviour: the twopoint source simulation produces the smallest lateral extent with approximately 25 diameters as compared with the double engine (32 diameters) and the complete aircraft simulation (42 diameters). This reinforces the fact that the streamwise vortices created by the engine have a significant impact on the dispersion process, creating sinusoidal instabilities that lead to breakups of the plume. These streamwise vortices also do most of the transport in the horizontal direction and are enhanced when the wing is present, creating wing-tip vortices. It must be stressed that the point source simulation of Koutsourakis et al. (2006) does not take into account geometrical effects of the engine, whereas the double-engine and the complete aircraft simulations include the modelling of the CFM56-3C-1 engine casings. Table 1 summarises the findings discussed through the paper and offers a comparison between the different simulations.

To give an overview of the vertical extent of the plume, Fig. 11 shows LIDAR results for a Boeing 777-200ER obtained at Manchester airport at different times. The Boeing 777-200ER is a larger airplane than the Boeing 737-300 and usually has two General Electric GE90-90B engines. The mass flow rate of these engines is about 4.3 times the CFM56-3C-1 engines and, from the ICAO engine emissions data table, emits approximately 7.25 times more $\mathrm{NO}_{\mathrm{x}}$ during the take-off phase. Fig. 11(b) illustrates that the particles backscattered by the scanned beam extend to about $86 \mathrm{~m}$ 
(92 diameters) in the vertical direction. This compares well with the results found earlier with the complete aircraft simulation, which showed a plume rise to about $80 \mathrm{~m}$ (86 diameters).

\begin{tabular}{|c|c|c|c|c|c|c|c|}
\hline & \multicolumn{2}{|c|}{$\begin{array}{c}\text { Point source } \\
\text { simulation } \\
\text { (Koutsourakis } \\
\text { et al., 2006) }\end{array}$} & \multicolumn{2}{|c|}{$\begin{array}{c}\text { Double- } \\
\text { engine } \\
\text { simulation }\end{array}$} & \multicolumn{2}{|c|}{$\begin{array}{c}\text { Complete } \\
\text { aircraft } \\
\text { simulation }\end{array}$} & \\
\cline { 2 - 8 } & $\begin{array}{c}\text { After } \\
\mathbf{1 0 s}\end{array}$ & $\begin{array}{c}\text { After } \\
\mathbf{4 0 s}\end{array}$ & $\begin{array}{c}\text { After } \\
\mathbf{1 0 s}\end{array}$ & $\begin{array}{c}\text { After } \\
\mathbf{4 2 s}\end{array}$ & $\begin{array}{c}\text { After } \\
\mathbf{1 0 s}\end{array}$ & $\begin{array}{c}\text { After } \\
\mathbf{4 2 s}\end{array}$ & \multicolumn{1}{|c|}{ Comments } \\
\hline $\begin{array}{c}\text { Plume } \\
\text { penetration } \\
\text { in } \\
\text { diameters }\end{array}$ & 430 & 2050 & 353 & 2043 & 333 & 2000 & $\begin{array}{l}\text { The complete aircraft geometry } \\
\text { restricts the plume penetration } \\
\text { downwind. }\end{array}$ \\
\hline $\begin{array}{c}\text { Spanwise } \\
\text { spread in } \\
\text { diameters }\end{array}$ & 25 & 36 & 32 & 50 & 42 & 54 & $\begin{array}{l}\text { Streamwise vortices created by } \\
\text { aircraft geometry enhance the } \\
\text { spanwise plume transportation. }\end{array}$ \\
\hline
\end{tabular}

Table 1 - Comparison of results between point source, double-engine and complete aircraft simulations

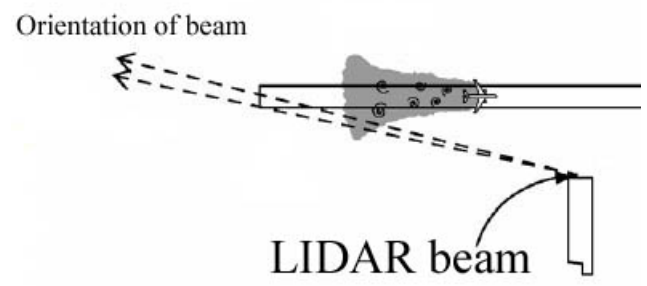

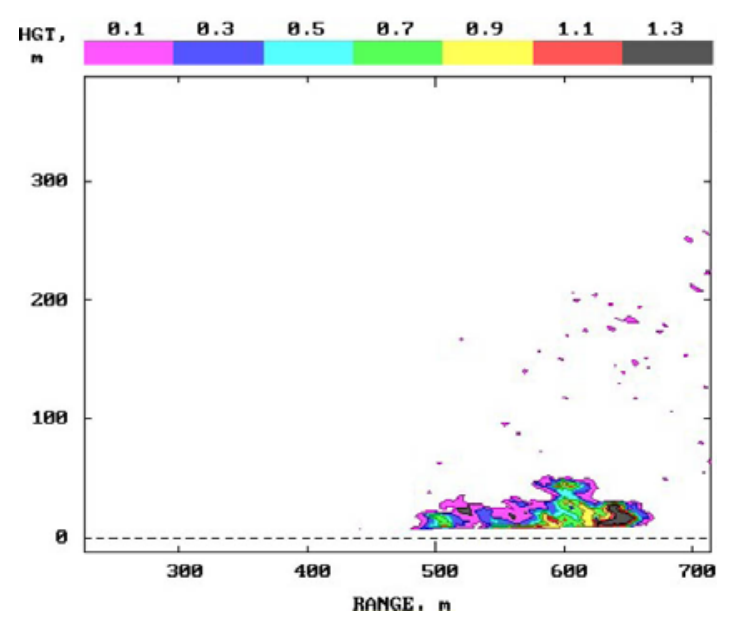

(a)

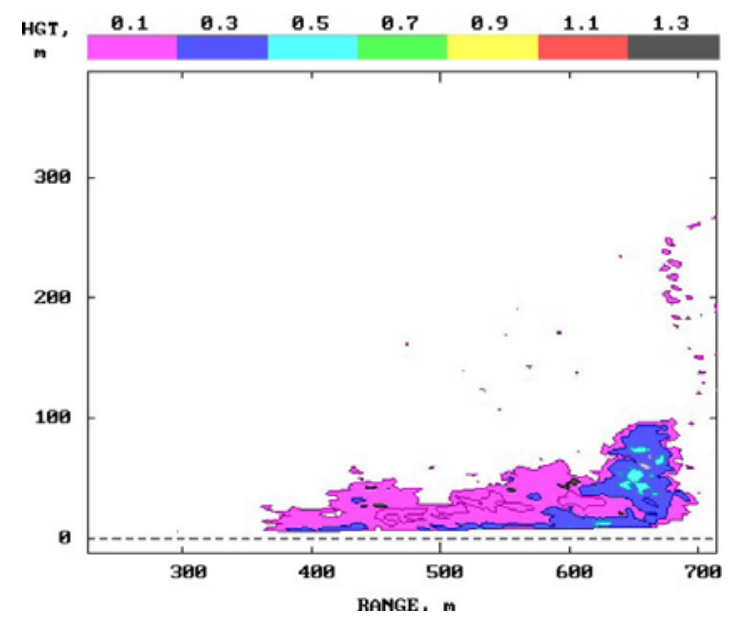

(b)

Fig. 11- LIDAR results for a Boeing 777-200ER at Manchester airport (Courtesy of Angus Graham, Manchester Metropolitan University)

The plume rise for the complete aircraft simulation compares well with the LIDAR results. Bearing in mind that the LIDAR results are for a Boeing 777, which is categorised as a large aircraft, the results for a medium-size aircraft like the Boeing 
737 should then be lower. The study of the previous time step, at 10s, confirms this behaviour with the results from the LIDAR measurements (44 diameters) shown in Fig. 11(a) being close to the results for the complete aircraft simulation (38 diameters). This confirms again the effects of a combination of vortices, after the break up process of the sinusoidal instability, and the influence of the streamwise vortices created by the horizontal stabilizer in the vertical dispersion. Table 2 summarises the findings discussed throughout the paper and offers a comparison between different simulations and the LIDAR results of a B777-200.

\begin{tabular}{|c|c|c|c|c|c|c|c|}
\hline & \multicolumn{2}{|c|}{$\begin{array}{l}\text { LIDAR } \\
\text { results for a } \\
\text { B777-200 }\end{array}$} & \multicolumn{2}{|c|}{$\begin{array}{l}\text { Double- } \\
\text { engine } \\
\text { simulation }\end{array}$} & \multicolumn{2}{|c|}{$\begin{array}{l}\text { Complete } \\
\text { aircraft } \\
\text { simulation }\end{array}$} & \multirow[b]{2}{*}{ Comments } \\
\hline & $\begin{array}{c}\text { After } \\
\text { 10s }\end{array}$ & $\begin{array}{c}\text { After } \\
\mathbf{4 2 s}\end{array}$ & $\begin{array}{c}\text { After } \\
\text { 10s }\end{array}$ & $\begin{array}{l}\text { After } \\
\text { 42s }\end{array}$ & $\begin{array}{c}\text { After } \\
\mathbf{1 0 s}\end{array}$ & $\begin{array}{l}\text { After } \\
\text { 42s }\end{array}$ & \\
\hline $\begin{array}{l}\text { Plume } \\
\text { rise in } \\
\text { diameters }\end{array}$ & 44 & 92 & 33 & 54 & 38 & 86 & $\begin{array}{l}\text { Combination of vortices has an } \\
\text { effect in the vertical plume } \\
\text { dispersion, which is enhanced } \\
\text { when the complete aircraft } \\
\text { geometry is added. }\end{array}$ \\
\hline
\end{tabular}

Table 2 - Comparison of results between LIDAR measurements, double-engine and complete aircraft simulations

\section{Conclusions}

The purpose of this paper was to present some results on emission dispersion for a complete Boeing 737-300 aircraft under a headwind configuration. The information obtained aimed at improving the understanding of the flow and dispersion behaviour for an aircraft in the take-off phase, and intends to provide an initial assessment on the use of CFD techniques as a tool to improve source dynamics representation.

At the very early stage of the simulation, the dispersion process is governed by spanwise vortices. The flow properties were very similar to those of a jet above the ground presented by Aloysius and Wrobel (2009) but, as the simulation progresses through time, geometrical effects start appearing.

At the end of the ICAO take-off time-in-mode (42s), the near field is still governed by the spanwise vortices but further downwind the "self-induced" jet rotation can be observed with counter-rotating streamwise vortices wrapping around the plume, creating sinusoidal instabilities leading to breakups. When this happens, the streamwise vortices were found to be the ones which transport the plume in the horizontal direction whereas a combination of all other vortices was found to affect its vertical dispersion. The effect of the wing tip and the horizontal stabilizer's tip was to enhance plume dispersion. Because of their distance from the engine exhaust, they will have different influences. The horizontal stabilizer will encounter the jet spread first, enhancing the vertical dispersion, whereas the wing-tip vortices will only affect the flow at large distances downwind.

The LES simulation of the complete aircraft also produced information on flow velocity, temperature and turbulence, which are major parameters to characterise source dynamics in any problem. In addition to this, the simulation could serve several other purposes, especially in terms of air traffic operations. Results can shed light on the strength of the wake turbulence when different types of aircraft take off 
and land. As a consequence, a proper time delay separation can be obtained for different classes of aircraft, thus improving airport traffic management.

In an airport environment, the need for better source dynamics representation exists for airplanes in movement during the take-off and landing phases, but it is also necessary when they are immobile using their auxiliary power unit. In this study, a non-reactive pollutant was introduced to simplify the problem but chemistry models exist for CFD simulations to predict chemical transformations associated with the dispersion process.

\section{Acknowledgment}

The work reported in this paper has been undertaken as part of the Airport Local Air Quality Studies (ALAQS) project commissioned and sponsored by EUROCONTROL. The authors would like to thank all the members of ALAQS consortium, especially Dr Ian Fuller from EUROCONTROL. The authors would also like to thank Dr Angus Graham from Manchester Metropolitan University for his LIDAR results.

\section{References}

Aloysius, S. S. (2008) On the use of near-field computational fluid dynamics for improving airport-related dispersion models. $\mathrm{PhD}$ Thesis, School of Engineering and Design, Brunel University, UK.

Aloysius, S.S., Pearce, D. and Wrobel, L.C. (2007) ALAQS - Comparison of CFD and Lagrangian dispersion methods - Simple scenario during take-off. Report EEC/SEE/2007/001, EUROCONTROL Experimental Centre, http://www.eurocontrol.int/eec/gallery/content/public/document/eec/report/20 07/032_ALAQS_comparison_of_CFD_and_Lagrangian_dispersion_methods. pdf.

Aloysius, S. S., Pearce, D., Wrobel, L.C. and Silue, M. (2006) Comparison of CFD with Lagrangian-based simulations for airfield emissions dispersion. Report, EUROCONTROL Experimental Centre.

Aloysius, S. and Wrobel, L.C. (2009) Comparison of flow and dispersion properties of free and wall turbulent jets for source dynamics characterisation. Environmental Modelling and Software 24:926-937.

Archer, R.D. and Saarlas, M. (1996) An introduction to aerospace propulsion. Prentice Hall.

Celikel, A., Duchene, N., Fuller, I., Silue, M., Fleuti, E., Hofmann, P. and Moore, T. (2004) Airport local air quality studies. Case study: Emission inventory for Zurich airport with different methodologies. Report EEC/SEE/2004/010, EUROCONTROL Experimental Centre.

Gerz, T., Holzapfel, F and Darracq, D. (2002) Commercial aircraft wake vortices. Progress in Aerospace Sciences 38:181-208.

Ghias, R., Rajat, M. and Haibo, D. (2005), Study of tip-vortex formation using largeeddy simulation. 43rd Fluid Dynamics Conference and Exhibition, AIAA2005-1280, Reno, NV.

Graham, A. and Raper, D. (2003) Air quality in airport approaches: Impact of emissions entrained by vortices in aircraft wakes. http://www.cate.mmu.ac.uk/documents/Publications/Woct03.pdf. 
Jenkinson, L., Simpkin, P. and Rhodes, D. (1999) Civil jet aircraft design. Butterworth-Heinemann.

Koutsourakis, N., Bartzis, J.G., Venetsanos, A. and Rafaildis, S. (2006) Computation of pollutant dispersion during an airplane take-off, Environmental Modelling and Software 21:486-493.

Penner, J.E, Lister, D.H., Griggs, D.J., Dokken, D.J. and McFarland, M. (1999) Aviation and the global atmosphere, http://www.grida.no/climate/ipcc/index.htm.

Rogers, H.L., Lee, D.S., Raper, D.W., Forster, P.M. de F., Wilson, C.W., Newton, P. (2002) The impact of aviation on the atmosphere. QINETIQ Report, QINETIQ/FST/CAT/TR021654.

Schäfer, K., Jahn, C., Sturm, P., Lechner, B. and Bacher, M. (2003) Aircraft emission measurements by remote sensing methodologies at airports. Atmospheric Environment 37:5261-5271. 